\title{
A study of the effects of dietary added cupric oxide on the laying, domestic fowl and a comparison with the effects of hydrated copper sulphate
}

\author{
BY N. JACKSON AND MARY H. STEVENSON \\ Agricultural and Food Chemistry Research Division, Department of Agriculture for \\ Northern Ireland, and The Queen's University of Belfast, Newforge Lane, \\ Belfast BT9 5PX, Northern Ireland
}

(Received 18 February 1980 - Accepted 27 May 1980)

\begin{abstract}
1. An experiment is reported in which copper, as cupric oxide, was fed to two breeds of laying hen for 336 d at levels equivalent to $150,300,450,600$ and $750 \mathrm{mg}$ added $\mathrm{Cu} / \mathrm{kg}$ diet. The results obtained were compared with those found using similar diets to which the $\mathrm{Cu}$ was added as $\mathrm{CuSO}_{4} . \mathrm{SH}_{2} \mathrm{O}$.

2. Addition of the CuO had no effoct on food intake, food conversion efficiency, body-weight or egg production. The $\mathrm{CuSO}_{4}$ addition caused the quadratic response of food intake and the adverse effects on food intake, egg production and body-weight noted in previous experiments.

3. The CuO had no effect on liver, kidney, ovary, oviduct or gizzard weight per unit body-weight while the CuSO, decreased these with the exception of gizzard weight which was significantly increased.

4. CuO addition did not affect liver $\mathrm{Cu}$ concentration but $\mathrm{CuSO}_{4}$ caused a substantial increase of liver $\mathrm{Cu}$ especially at the $750 \mathrm{mg} \mathrm{Cu} / \mathrm{kg}$ level of addition.

5. CuO addition had no effect on liver lipid concentration but this was depressed at the highest level of CuSO, addition. Effects on individual fatty acids are presented but no specific conclusions have been reached.
\end{abstract}

The use of copper compounds as growth stimulants in pig diets has been studied for many years but their effects in poultry have been less thoroughly investigated.

Information about the effects of supplementing laying-hen diets with $\mathrm{Cu}$ compounds is limited and has been reviewed recently (Jackson, 1977; Jackson et al. 1979; Stevenson \& Jackson, $1980 a, b$ ). In these experiments the effects of added dietary copper sulphate on food and water intakes, weight gains, egg production and organ weights have been investigated. In addition effects of the $\mathrm{Cu}$ salt on the levels of $\mathrm{Cu}$ and other minerals in certain tissues of the laying hen have been studied and pathological effects on organs have also been investigated.

The effects of dietary $\mathrm{Cu}$ supplementation on porcine carcass quality have been reviewed by Braude (1967) who concluded that most of the evidence available indicated that $\mathrm{Cu}$ had no adverse effects. However, Taylor \& Thomke (1964) and Elliott \& Bowland (1968) have shown that the back fat of pigs given $\mathrm{CuSO}_{4}$-supplemented diets is softer than those receiving no $\mathrm{Cu}$ supplement. These changes were associated with increases in the oleic acid: stearic acid value in both the inner and outer layers of back fat (Christie \& Moore, 1969). Husbands (1972) gave chicks $227 \mathrm{mg}$ added $\mathrm{Cu} / \mathrm{kg}$ diet and Elliott \& Bowland (1972) gave rats $250 \mathrm{mg}$ supplemental dietary $\mathrm{Cu}$. The $\mathrm{Cu}$ was given to both species as sulphate and neither showed any significant changes in the fatty acid composition of subcutaneous fat.

In the present study the effects, in the laying hen, of cupric oxide were investigated and compared with the effects of $\mathrm{CuSO}_{4}$. The effects of the supplements on body and liver fat composition were also investigated. 


\section{EXPERIMENTAL}

The experiment commenced on 30 December 1977 and was carried out for $12 \times 28$ d periods. Two hundred and sixty-four 19-week-old laying hens previously vaccinated against Marek's disease, infectious bronchitis and epidemic tremors and comprising 132 white (Shaver 288) and 132 brown (Warren Studler SSL) birds were placed in galvanized-iron cages fitted with individual food troughs and nipple drinkers. The lighting regimen used was $15 \mathrm{~h}$ light and $9 \mathrm{~h}$ darkness. The battery house was unheated, the minimum recorded winter temperature being $2^{\circ}$ and the maximum summer temperature $28^{\circ}$. At 26 weeks of age, when all the hens had been laying for at least 2 weeks, they were randomly allocated to one of eleven treatment groups giving twelve hens of each breed per treatment. The diets, fed ad lib., were the control diet which was essentially that described by Jackson (1977) and this diet to which was added $150,300,450,600$ or $750 \mathrm{mg} \mathrm{Cu} / \mathrm{kg}$ either as AR grade CuO powder (treatments 2-6) or as AR grade $\mathrm{CuSO}_{4} .5 \mathrm{H}_{2} \mathrm{O}$ (treatments $7-11$ ) ground to the specification reported by Jackson (1977).

The control diet contained $(/ \mathrm{kg}) 158.5 \mathrm{~g}$ crude protein $(\mathrm{N} \times 6.25), 14 \mathrm{mg} \mathrm{Cu}, 124 \mathrm{mg}$ zinc, $239 \mathrm{mg}$ iron, $32.2 \mathrm{~g}$ calcium, $5.4 \mathrm{~g}$ phosphorus and had a calculated metabolizable energy (ME) content of $11.4 \mathrm{MJ} / \mathrm{kg}$. Egg production was recorded daily and the eggs weighed twice weekly. The hens were weighed initially and at the end of each $28 \mathrm{~d}$ period and mean body-weight obtained from these observations. Food intake was recorded for each $28 \mathrm{~d}$ period. During the last period four eggs from each breed for each treatment were randomly selected and the $\mathrm{Cu}$ concentrations in the dry matter, less the shell and membranes, measured.

After 48 weeks, four birds of each breed from each treatment were randomly selected and killed by decapitation. Liver, kidneys, oviduct, ovary and gizzard were removed and weighed. Livers and kidneys were dried at $100^{\circ}$. Liver lipid and lipid from the fatty tissue adhering to the gizzard were extracted by the method of Folch et al. (1957). The lipid extracts were subjected to fatty acid analyses using gas-liquid chromatography. Blood serum $\mathrm{Cu}$ determination and the food, tissue and egg mineral analyses were carried out as described by Stevenson \& Jackson $(1980 a)$.

The results were subjected to analysis of variance. Log transformations were carried out for those variables which exhibited variance heterogeneity. At zero added $\mathrm{Cu}$ the oxide and sulphate treatments coincide and so this level of $\mathrm{Cu}$ was omitted in determining the significance of interactions between the factors. However, in determining responses to $\mathrm{Cu}$ levels the complete range of $\mathrm{Cu}$ from 0 to $750 \mathrm{mg}$ added $\mathrm{Cu} / \mathrm{kg}$ was used.

\section{RESULTS}

Mortality in the experiment was very low $(1.9 \%)$ and all those birds which died were white (Shaver 288) hens receiving diets high in added $\mathrm{CuSO}_{4}$.

The results for food intake, egg production and food conversion, expressed as bird means, are presented in Table 1.

Total food intake showed no definite relationship with the level of $\mathrm{CuO}$ addition to the diet although it showed a quadratic response $(P<0.001)$ to added $\mathrm{CuSO}_{4}$, the production of the white and brown hens being respectively reduced to 51 and $59 \%$ of the control values at the $750 \mathrm{mg} / \mathrm{kg}$ level of $\mathrm{Cu}$ supplementation.

The numbers of eggs produced and the total egg weight were significantly affected by additive treatment $(P<0.001)$. No evidence of any effect due to the $\mathrm{CuO}$ was apparent. The over-all effect on total egg weight was due to the depression of egg production by the $\mathrm{CuSO}_{4}$ and the negative linear relationship $(P<0.001)$ between mean period mean egg weight and the level of added dietary $\mathrm{CuSO}_{4}$. 
Effects of dietary $\mathrm{CuO}$ in the laying hen

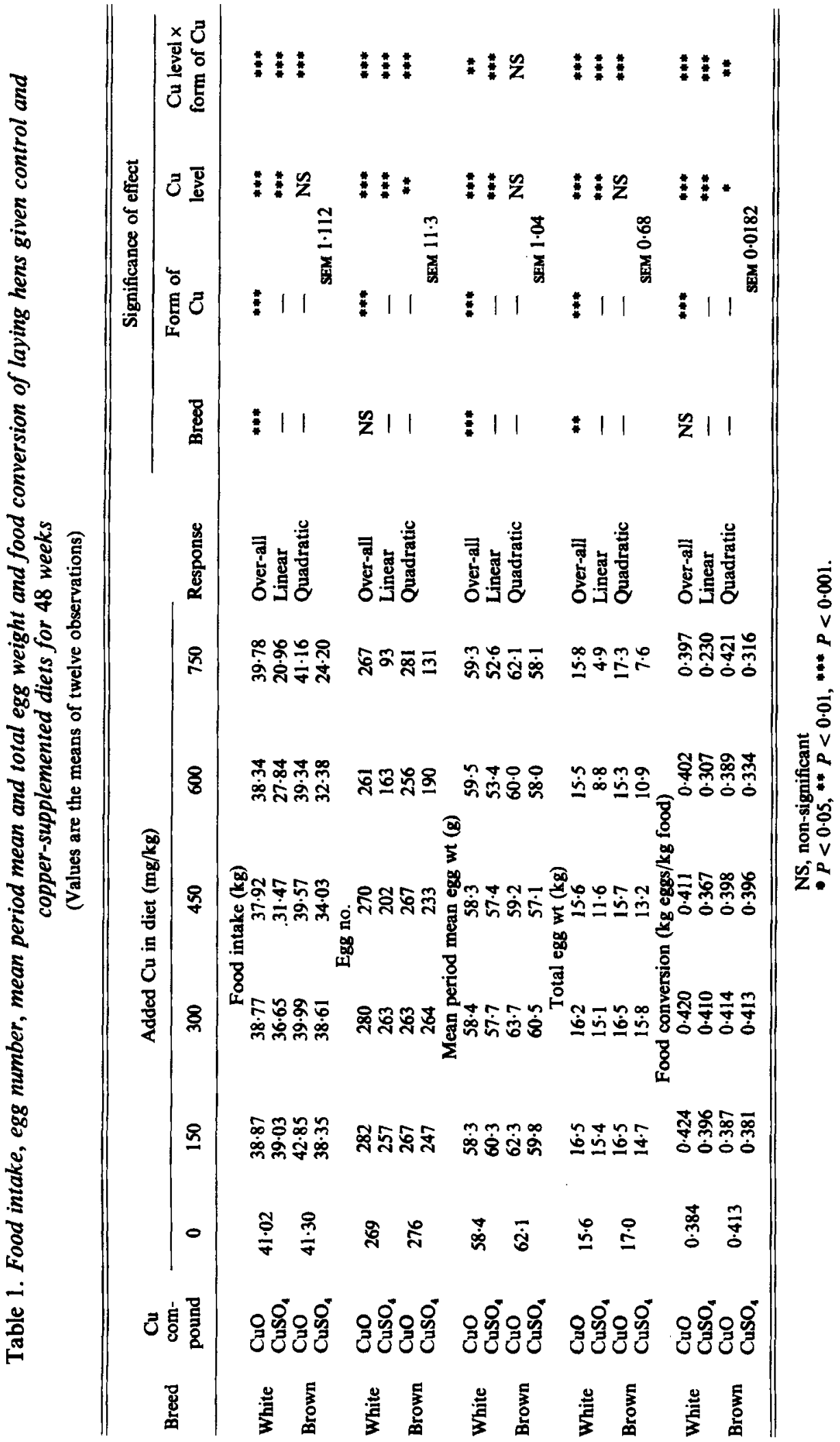


N. JACKSON AND MARY H. STEVEnSON

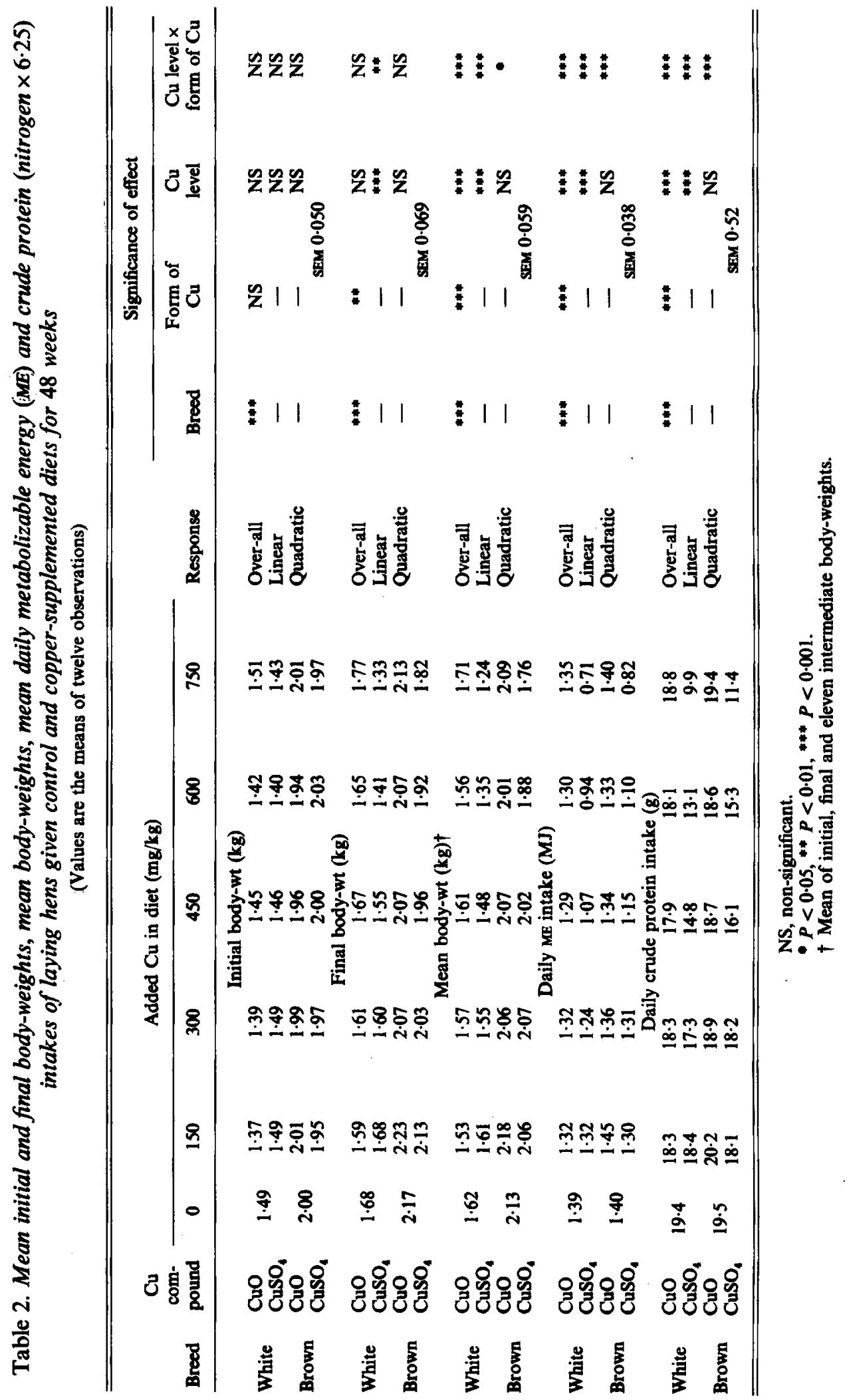


Effects of dietary $\mathrm{CuO}$ in the laying hen

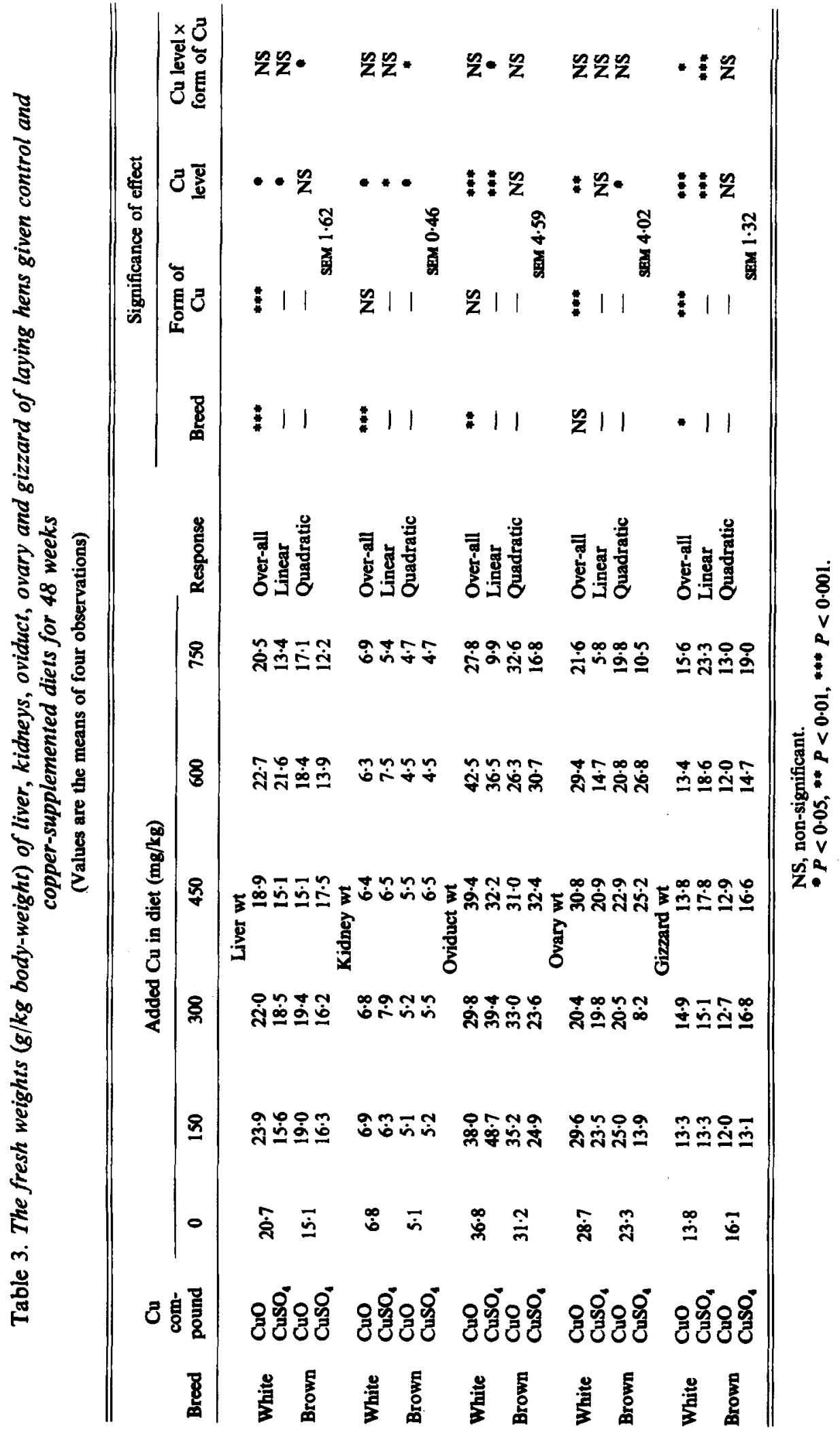


N. Jackson and Mary H. Stevenson

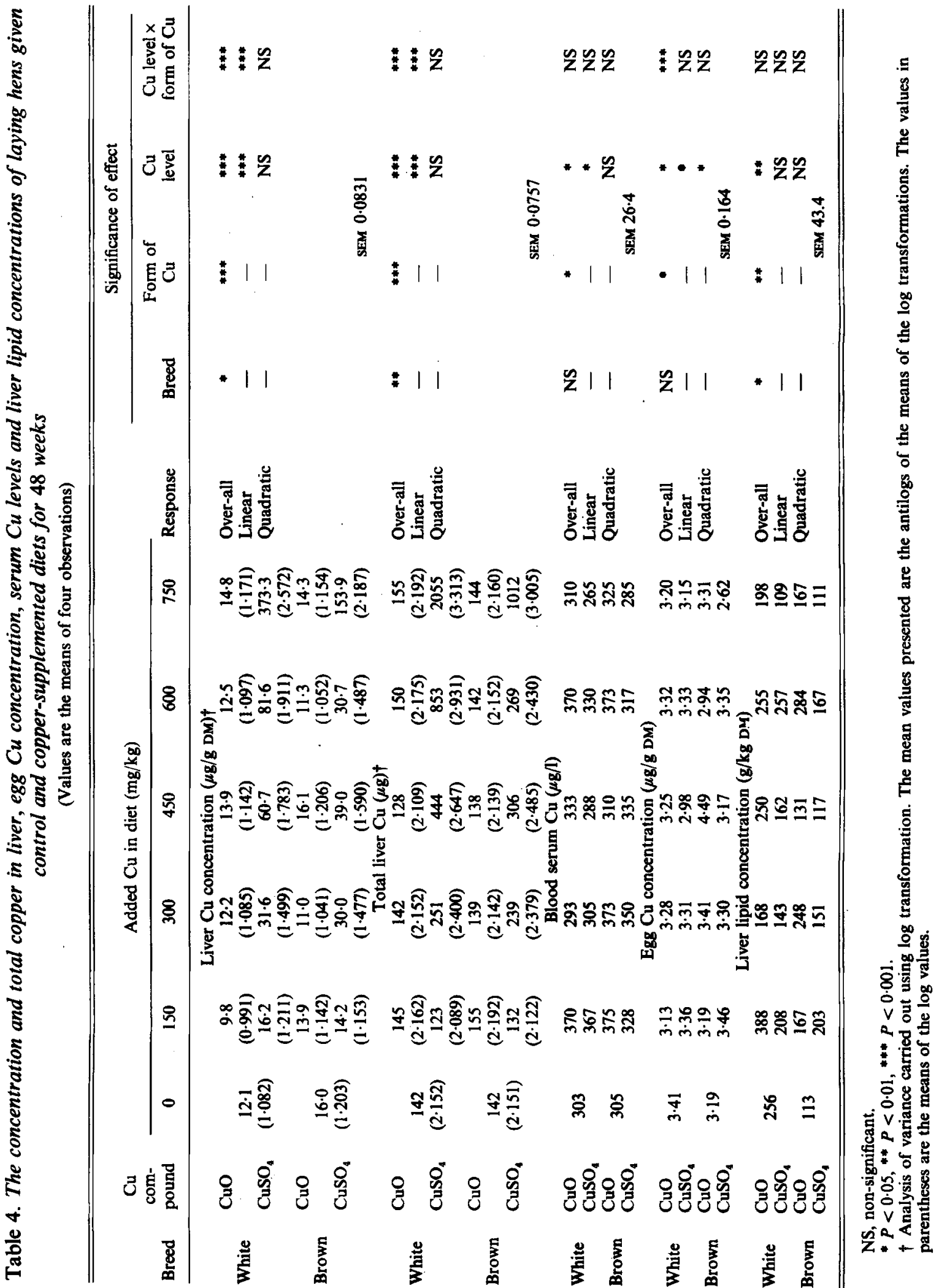


There was no evidence of any effect of the $\mathrm{CuO}$ on food conversion efficiency while for $\mathrm{CuSO}_{4}$ addition there was a quadratic relationship $(P<0.01)$, the maximum food conversion occurring at $178 \mathrm{mg}$ added $\mathrm{Cu} / \mathrm{kg}$ diet.

The mean initial and final body-weights, mean body-weights, daily ME intakes and daily crude protein intakes are shown in Table 2.

The mean initial weights of the white and brown birds were 1.44 and $1.98 \mathrm{~kg}$ respectively. Although dietary treatment depressed final body-weight $(P<0.001)$ no specific effect was noted due to added $\mathrm{CuO}$ in the diet. The added $\mathrm{CuSO}_{4}$ showed a linear relationship $(P<0.01)$ with final body-weight. The mean final body-weights for the white and brown birds were 1.60 and $2.05 \mathrm{~kg}$ respectively. The addition of the two highest levels of CuSO, caused a marked fall in body-weight between treatment periods 4 and 10 which is reflected in the mean body-weights.

The fresh weights of liver, kidneys, oviduct, ovary and gizzard/kg body-weight are given in Table 3.

The $\mathrm{CuO}$ had no significant effect on liver fresh weight or kidney weight per unit body-weight. The negative linear relationship of liver fresh weight to additive $(P<0.05)$ was obviously mainly due to the quadratic response to $\mathrm{CuSO}_{4}(P<0.05)$ and was more pronounced in the white than in the brown birds. The former had the greater liver mass per unit body-weight $(P<0.001)$. The over-all effect of additive on kidney fresh weight per unit body-weight was quadratic $(P<0.05)$ and this effect was also due to the quadratic response to $\mathrm{CuSO}_{4}(P<0.05)$.

The $\mathrm{CuO}$ had no statistically significant effect on the oviduct, ovary or gizzard weights. The additive effect on oviduct weight was linear $(P<0.001)$ the $\mathrm{CuSO}_{4}$-fed hens showing a very marked oviduct weight depression at the highest level of addition. This effect was also seen in the ovary the over-all relationship being quadratic $(P<0.05)$. Gizzard weight per unit body-weight was increased linearly by the $\mathrm{CuSO}_{4}(P<0.001)$.

The $\mathrm{Cu}$ analytical values are presented in Table 4 together with the liver lipid concentrations. $\mathrm{CuO}$ had no significant effect on either liver $\mathrm{Cu}$ concentration or content but the $\mathrm{CuSO}_{4}$ had a very dramatic positive linear effect $(P<0.001)$ on both these factors in both breeds.

Over-all, a negative linear relationship was found between the additive and blood serum $\mathrm{Cu}(P<0.05)$, the respective mean values of the oxide- and sulphate-fed birds being 343 and $317 \mu \mathrm{g} / \mathrm{l}$. The effect of the additive on egg $\mathrm{Cu}$ concentration is not readily evident although the relationship was quadratic $(P<0.05)$.

The liver lipid concentration was affected by level of additive $(P<0.01)$. The $\mathrm{CuO}$ had no effect but in the instance of the sulphate it was depressed at the $750 \mathrm{mg} \mathrm{Cu} / \mathrm{kg}$ level of addition.

Tables 5 and 6 contain the proportions of certain fatty acids present in the triglycerides of the liver and body fat respectively. The 14:0 and 16:0 fatty acids show a linear decrease with additive level $(P<0.01$ and $P<0.001$ respectively) while the 18:0, 18:3 and 20:4 fatty acids increased $(P<0.05, P<0.05$ and $P<0.01$ respectively). In the instance of the 18:2 fatty acid a quadratic response $(P<0.05)$ was found, the levels of the additive corresponding to 450 and $600 \mathrm{mg} \mathrm{Cu} / \mathrm{kg}$ diet resulting in the two lowest proportions of this acid. The over-all effect of additive on the 18:1 fatty acid was significant $(P<0.01)$.

In the body fat the 18:0 and 18:1 fatty acids showed a positive linear response to the additives $(P<0.01)$ while the 16:0 fatty acid showed a positive quadratic response and the 18:2 fatty acid showed a negative quadratic response (both $P<0.05$ ). The 20:4 fatty acid in the body fat was unaffected by additive but was significantly lower in the white than in the brown birds $(P<0.01)$. 
Effects of dietary $\mathrm{CuO}$ in the laying hen

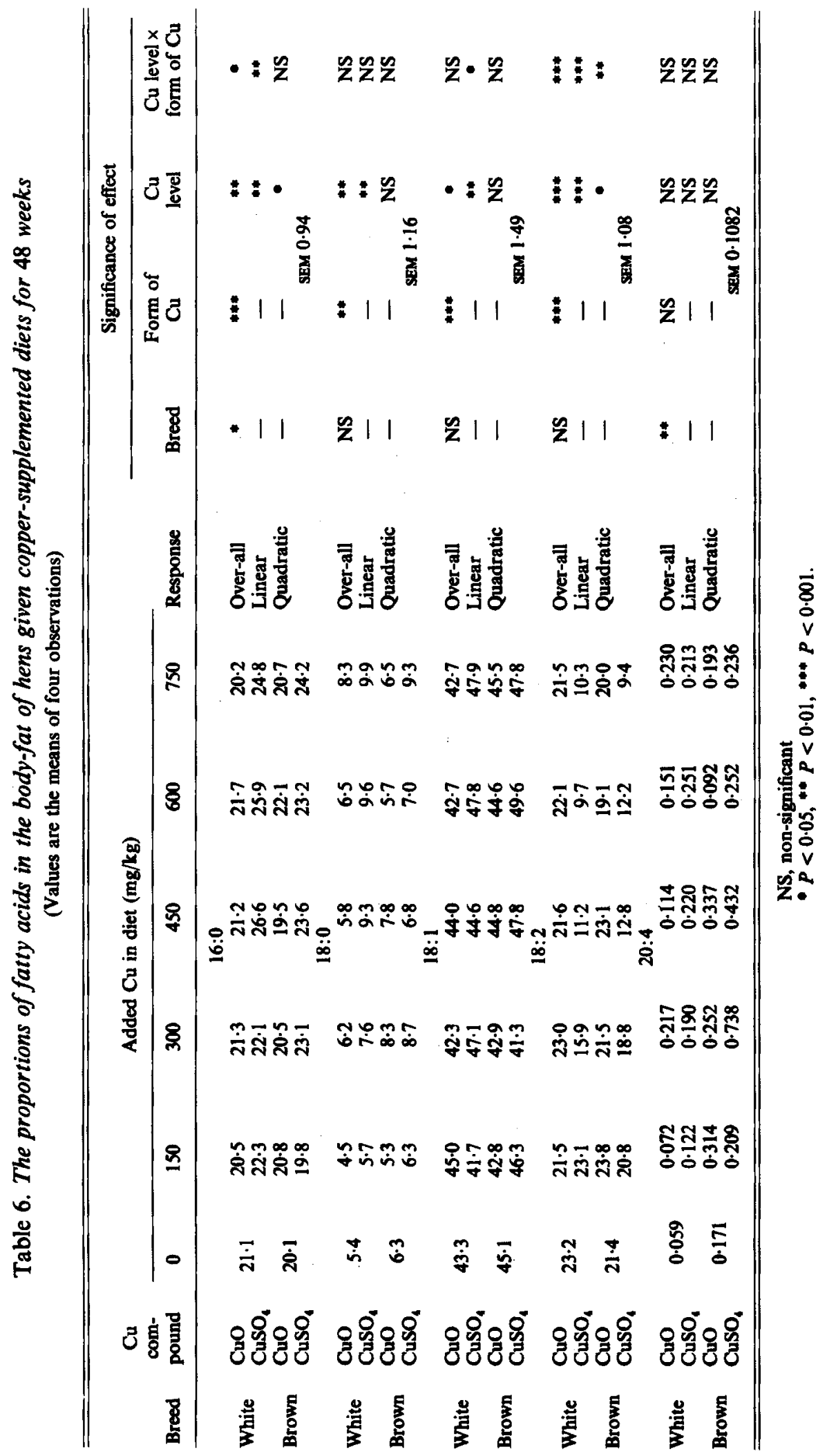


DISCUSSION AND CONCLUSIONS

The mortality results suggest that the white birds were more susceptible than the brown birds to the toxic effects of the added $\mathrm{CuSO}_{4}$.

The lack of effect on food intake resulting from the $\mathrm{CuO}$ addition is in contrast to the depression caused by the $\mathrm{CuSO}_{4}$; an effect which is already well documented (Jackson, 1977; Jackson et al. 1979; Stevenson \& Jackson, 1980a, b).

With regard to egg numbers, mean egg weight and total egg weight, again the lack of response to $\mathrm{CuO}$ contrasted to the effects of the $\mathrm{CuSO}_{4}$. The occurrence of an increase in egg numbers and total egg weight at lower values (maximum 257.5 eggs at $75 \mathrm{mg}$ added $\mathrm{Cu} / \mathrm{kg}$ diet) and the severe depression observed at the higher levels of $\mathrm{CuSO}_{4}$ agrees with the observations of Jackson (1977), Jackson et al. (1979), and Stevenson \& Jackson $(1980 a, b)$. The depressing effect of $\mathrm{CuSO}_{4}$ on mean period mean egg weight is in accord with the results of Thomas et al. (1974) and Jackson et al. (1979).

The lack of response of food conversion efficiency to the $\mathrm{CuO}$ may be at variance with the results of Mehring et al. (1960) who reported an increased efficiency of food conversion in broilers fed a copper oxide at levels below $600 \mathrm{mg} \mathrm{Cu} / \mathrm{kg}$ diet. However, it is not clear if the oxide used by these authors was the divalent oxide. Guenthner et al. (1978) added cuprous oxide to the diets of turkey poults and found at fairly low levels (up to $240 \mathrm{mg} \mathrm{Cu} / \mathrm{kg}$ diet) that an improved food conversion ratio occurred up to 15 weeks of age. The quadratic effect of $\mathrm{CuSO}_{4}$ on food conversion efficiency agrees with the results of Jackson et al. (1979) in the laying hen and Fisher et al. (1971) in the broiler.

The contrasting effects of $\mathrm{CuO}$ and $\mathrm{CuSO}_{4}$ on body-weight and egg production appear to be mainly due to the fact that the $\mathrm{CuSO}_{4}$ caused a severe depression of food intake above $300 \mathrm{mg}$ added $\mathrm{Cu} / \mathrm{kg}$ diet. The depression of mean period mean egg weight is a factor in total egg weight reduction and may result from the effect of $\mathrm{CuSO}_{4}$ on lipid synthesis. The effect of depression of intake is clearly demonstrated when the values for ME and crude protein intake (Table 2) are compared with the Agricultural Research Council (1975) requirements for maintenance and production. The existing results do not indicate whether the effects on production are merely due to the reduced intakes and a direct effect on lipid synthesis or whether there is another effect, for example, on the hormonal systems involved. However, results of paired-feeding experiments with broilers (Fisher $e t$ al. 1971) show that reduced growth was due to lower intakes resulting from $\mathrm{CuSO}_{4}$ addition.

The depressing effect of $\mathrm{CuSO}_{4}$ on liver weight (Table 3) in the domestic fowl has been observed previously (Jackson, 1977; Jackson et al. 1979; Stevenson \& Jackson 1980a, b). The lack of a coincidental response in kidney weight is surprising but agrees with the results of other experiments reported previously.

Of the eighty-eight birds examined, twelve were not laying in the week before slaughter. Only one of these was on the $\mathrm{CuO}$ treatment while seven were in the groups receiving the two highest levels of $\mathrm{CuSO}_{4}$ : The lack of effect of $\mathrm{CuO}$ on the oviduct and ovary was to be expected in view of the lack of effect on egg production. The oviduct regression at the highest level of $\mathrm{CuSO}_{4}$ addition agrees with previous observations (Jackson, 1977; Jackson et al. 1979; Stevenson \& Jackson, $1980 a, b$ ). The low ovary weights for the brown birds given $\mathrm{CuSO}_{4}$ equivalent to 300 and $750 \mathrm{mg}$ added $\mathrm{Cu} / \mathrm{kg}$ diet indicate that some of these birds were going out of lay, oviduct regression being less advanced than ovarian regression.

The lack of effect of CuO on gizzard weight is presumably due to the fact that the oxide is virtually insoluble in the $\mathrm{pH}$ range $(2 \cdot 0-3 \cdot 5)$ in the gizzard (Sturkie, 1976). The gizzard weight increase in the presence of the $\mathrm{CuSO}_{4}$ has previously been noted (Jackson et al. 1979; Stevenson \& Jackson $1980 a, b$ ) and may be attributed to effects resulting from the high solubility of the salt at the $\mathrm{pH}$ of the gizzard. Associated pathological effects have been noted 
in broilers (Fisher et al. 1973), in chicks (Poupoulis \& Jensen, 1976) and in laying hens (Stevenson \& Jackson, $1980 a, b$ ).

It seems apparent that the failure of $\mathrm{CuO}$ to affect liver $\mathrm{Cu}$ concentration is related to its lack of solubility even under the wide ranges of $\mathrm{pH}$ encountered in the digestive tract (Sturkie, 1976). Although the liver Cu concentration values (Table 4) suggest some increases at the lower levels of $\mathrm{CuSO}_{4}$ addition the results support the findings of previous work that a threshold exists in the region of $250-600 \mathrm{mg}$ added $\mathrm{Cu}$ as $\mathrm{CuSO}_{4} / \mathrm{kg}$ diet above which liver $\mathrm{Cu}$ concentration rises sharply (Jackson et al. 1979; Stevenson \& Jackson, 1980a). A similar phenomenon has been reported for other species (Milne \& Weswig, 1968; Ritchie et al. 1963).

The blood serum $\mathrm{Cu}$ levels showed considerable variation and although the over-all additive response was linear it is difficult to ascribe specific effects to the additives. Previous experiments have also led to rather similar inconclusive effects (Jackson, 1977; Jackson et al. 1979; Stevenson \& Jackson, 1980a). Difficulty also prevails in passing comment on the quadratic response of egg $\mathrm{Cu}$ concentration to additive. Thomas et al. (1974) and Griminger (1977) did not find any significant effect of dietary $\mathrm{CuSO}_{4}$ on egg $\mathrm{Cu}$ concentration.

The lack of effect of $\mathrm{CuO}$ on liver lipid concentration is not surprising since the depression of the liver lipid is obviously related to effects on the oviduct, ovary and egg production. The decrease in liver lipid caused by high dietary $\mathrm{CuSO}_{4}$ has been observed previously in this laboratory (Jackson et al. 1979; Stevenson \& Jackson, $1980 a, b$ ). This is attributed to the fact that in the fowl the liver is the main site of fatty acid synthesis (Goodridge, 1968; O'Hea \& Leveille, 1969) and of the lipids associated with oestrogen-induced lipidaemia (Ranney \& Chaikoff, 1951).

In earlier studies on the pig (Elliott \& Bowland, 1968; Christie \& Moore, 1969) it was found that when $\mathrm{Cu}$ was added to the diet as $\mathrm{CuSO}_{4}$ a softer back fat was found which was due to the presence of an increase in the 16:1 and 18:1 fatty acids. In the present experiment it is difficult to state whether the observed effects on lipid composition are direct effects mainly due to the dietary $\mathrm{CuSO}_{4}$ or secondary effects due to reduced food intake.

The fact that the $\mathrm{CuSO}_{4}$ was responsible for most of the effects observed in this experiment may be attributed to the solubility and availability differences between the predominantly insoluble $\mathrm{CuO}$ and the ionizable $\mathrm{CuSO}_{4}$ under the conditions occurring in the digestive tract of the domestic fowl. A similar relationship between the solubility of these two salts has been reported by Willingham \& Hill (1970). The fact that it is the $\mathrm{Cu}$ ion rather than the sulphate which causes a growth stimulus in the pig has been shown by Hawbaker et al. (1959). However, although the results of the present experiment show that dietary CuO has very little pharmacological activity in the laying hen it fails to demonstrate if the activity observed for $\mathrm{CuSO}_{4}$ is due to the $\mathrm{Cu}$ or sulphate ion.

The authors thank Mrs R. Park, Mr G. McC. Kirkpatrick and Mr W. Graham for technical assistance, their colleagues in the Agricultural Biometrics Division for assistance with statistical analyses and the Trustees of the Agricultural Research Institute, Hillsborough, Co. Down for providing facilities for the laying experiment.

REFERENCES

Agricultural Research Council (1975). The Nutrient Requirements of Farm Livestock No. 1, Poultry. London: H.M. Stationery Office.

Braude, R. (1967). World Rev. Anim. Prod. 3, 69.

Christie, W. W. \& Moore, J. H. (1969). Lipids 4, 345.

Elliott, J. I. \& Bowland, J. P. (1968). J. Anim. Sci. 27, 956.

Elliott, J. I. \& Bowland, J. P. (1972). Can. J. Anim. Sci. 52, 97.

Fisher, C., Laursen-Jones, A. P., Hill, K. J. \& Hardy, W. S. (1973). Br. Poult. Sci. 14, 55.

Fisher, C., Wise, D. \& Filmer, D. G. (1971). 14th Wld's Poult. Congr. Madrid p. 759. 
Folch, J., Lees, J. \& Sloane Stanley, C. H. (1957). J. biol. Chem. 226, 497.

Goodridge, A. F. (1968). Am. J. Physiol. 214, 897.

Griminger, P. (1977). Poult. Sci. 56, 359.

Guenthner, E., Carlson, C. W. \& Emerick, R. J. (1978). Poult. Sci. 57, 1313.

Hawbaker, J. A., Speer, V. C., Jones, J. D., Hays, V. W. \& Catron, D. V. (1959). J. Anim. Sci. 18, 1505 Abstr. Husbands, D. R. (1972). Br. Poult. Sci. 13, 201.

Jackson, N. (1977). Br. J. Nutr. 38, 93.

Jackson, N., Stevenson, M. H. \& Kirkpatrick, G. McC. (1979). Br. J. Nutr. 42, 253.

Mehring, A. L., Brumbaugh, J. H., Sutherland, A. J. \& Titus, H. W. (1960). Poult. Sci. 39, 713.

Milne, D. H. \& Weswig, P. H. (1968). J. Nutr. 95, 429.

O'Hea, E. K. \& Leveille, G. A. (1969). Comp. Biochem. Physiol. 30, 149.

Poupoulis, C. \& Jensen, L. S. (1976). Poult. Sci. 55, 113.

Ranney, R. E. \& Chaikoff, I. C. (1951). Am. J. Physiol. 165, 600.

Ritchie, H. D., Luecke, R. W., Baltzer, B. V., Miller, E. R., Ullrey, D. E. \& Hoefer, J. A. (1963). J. Nutr. $79,117$.

Stevenson, M. H. \& Jackson, N. (1980a). Br. J. Nutr. 43, 205.

Stevenson, M. H. \& Jackson, N. (1980b). Br. J. Nutr. 43, 551.

Sturkie, P. D. (ed.) (1976). In Avian Physiology, 3rd ed. p. 196-209. New York: Springer-Verlag.

Taylor, M. \& Thomke, S. (1964). Nature, Lond. 201, 1246.

Thomas, M. C., Norvell, M. J., Calvert, C. C. \& Goatcher, W. D. (1974). Poult. Sci. 53, 1984 Abstr.

Willingham, H. E. \& Hill, C. H. (1970). Proc. Maryland Nutr. Conf. Fd Mfr. p. 32. 